\title{
Antiplatelet Agents in Sepsis-Putting it all together: A Call to Action
}

\author{
Nishant R Tiwari ${ }^{1}$, Kaustubh S Chaudhari ${ }^{2}$, Richa Sharma ${ }^{3}$, Kevin P Haas ${ }^{4}$, Vivek R Sharma ${ }^{5}$
}

Keywords: Aspirin, Intensive care, Intensive care unit, Sepsis, Septic shock.

Indian Journal of Critical Care Medicine (2020): 10.5005/jp-journals-10071-23450

To the Editor,

Sepsis is the most common cause of death in intensive care settings in the United States. It has a substantial effect on healthcare expenditure with more than 20 billion USD spent on inpatient care in 2011 alone. ${ }^{1}$ Antiplatelet agents are the principal drugs for prevention of atherosclerotic diseases; however, their role in sepsis management remains limited by lack of clinical data. The role of platelet activation and the potential value of antiplatelet therapy in sepsis are the focus of this letter by which we hope to ignite interest in further research and clinical guideline development.

This immunoinflammatory role of platelets extends beyond their ability to form clots. $^{2-4}$ Inflammatory reactions seen in sepsis were found to be initiated in part by platelets. ${ }^{2}$ Activated platelets cause stimulation of various inflammatory cells by releasing their contents. They were found to have an important role in formation of neutrophil extracellular traps (NETs), one of the key mediators of microvascular dysfunction and intravascular coagulation in sepsis. ${ }^{2}$ This warrants consideration of antiplatelet agents as a therapy to optimize sepsis management.

Two meta-analyses showed statistically and clinically significant reduction in mortality, incidence of sepsis, and acute respiratory distress syndrome (ARDS) following the use of antiplatelet agents in the critically ill. ${ }^{5,6}$ One study showed a reduction in hospitalization duration in patients of community-acquired pneumonia who were on antiplatelet drugs. ${ }^{7}$ This data make a strong case for exploring the use of antiplatelet drugs in critically ill patients as an attempt to optimize clinical outcomes and potentially reduce the cost of treatment.

Aspirin or acetylsalicylic acid (ASA), the most studied antiplatelet drug, inhibits cyclo-oxygenase irreversibly, thus decreasing production of thromboxane A2 (TXA2), a potent activator of platelets. Additionally, ASA controls inflammation by inhibiting leukotrienes and other mediators of inflammation. Low-dose ASA works at molecular level, inhibits expression of nuclear factor-kappa B (NF-kB), which as a result, causes decrease in production of tumor necrosis factor-a (TNF- $\mathrm{a}$ ), blunting a pathway of inflammation. ${ }^{8}$ There have been multiple animal and retrospective studies suggesting survival benefit of ASA in sepsis. ${ }^{2,6}$ However, the amount of randomized controlled trials (RCTs) studying the safety and efficacy of ASA in sepsis is exiguous., ${ }^{9,10}$

Clopidogrel and ticagrelor prevent platelet aggregation by selectively blocking P2Y12 receptors. P2Y12 receptor blockade inhibits formation of platelet-monocyte aggregates, which are one of the major mediators of inflammation. ${ }^{11}$ Animal research involving P2Y12 blockers has shown significant reduction in sepsis-related morbidity and mortality, while separate human research concurred with reduced systemic inflammation and thrombosis. ${ }^{11-13}$ Such data raise the possibility that inhibition of platelet function may improve
${ }^{1}$ Department of Internal Medicine, Byramjee Jeejeebhoy Government Medical College, Pune, Maharashtra, India

${ }^{2}$ Department of Internal Medicine, University of Oklahoma Health Sciences Center, Oklahoma, USA

${ }^{3}$ Department of Ophthalmology, Byramjee Jeejeebhoy Government Medical College, Pune, Maharashtra, India

${ }^{4}$ Department of Pulmonary and Critical Care Medicine, University of Illinois at Chicago, Chicago, Illinois, USA

${ }^{5}$ Department of Hematology and Oncology, James Graham Brown Cancer Center, University of Louisville, Louisville, Kentucky, USA

Corresponding Author: Nishant R Tiwari, Department of Internal Medicine, Byramjee Jeejeebhoy Government Medical College, Pune, Maharashtra, India, Phone: +91 9049355543, e-mail: dr.nishant. tiwari.1996@gmail.com

How to cite this article: Tiwari NR, Chaudhari KS, Sharma R, Haas KP, Sharma VR. Antiplatelet Agents in Sepsis-Putting it all together: A Call to Action. Indian J Crit Care Med 2020;24(6):483-484.

Source of support: Nil

Conflict of interest: None

outcomes in patients having a systemic infection. GPIlb/Illa receptor antagonists have also shown cytoprotective effects in lungs and spleen of mice with sepsis in both in vivo and ex vivo models. ${ }^{14}$ However, a human correlation of this effect is yet to be studied.

Current research on use of antiplatelet agents is vastly confounded by selection bias due to lack of standardized definition of what constitutes "critically ill" in septicemia. ${ }^{5,6}$ Further, variation in doses of antiplatelet agents for septicemia or patients on lifetime low-dose or over-the-counter aspirin or discontinuation due to bleeding make calibration of dosages in trials difficult. ${ }^{15}$ Antiplatelet agents are more effective in gram-positive sepsis due to higher platelet activation while their efficacy is lower when complicated by disseminated intravascular coagulation. ${ }^{5,10}$ The presence of comorbidities makes outcomes increasingly difficult to compare. While most studies on clopidogrel and GPIIb/IIla inhibitors are in animals, human "volunteer" studies have depended on bolus endotoxin administration. While this mimics human endotoxemia, it can barely reproduce the complexity of septicemia. ${ }^{10}$ Lack of prospective intervention trials makes the results merely hypothesisgenerating and at best exploratory in value.

While RCTs comparing the use of antiplatelet agents in sepsis are ideal, systemic reviews and meta-analysis may provide valuable information. Development of clinical guidelines for the use of antiplatelet agents in sepsis, even if derived from expert consensus

(c) The Author(s). 2020 Open Access This article is distributed under the terms of the Creative Commons Attribution 4.0 International License (https://creativecommons. org/licenses/by-nc/4.0/), which permits unrestricted use, distribution, and non-commercial reproduction in any medium, provided you give appropriate credit to the original author(s) and the source, provide a link to the Creative Commons license, and indicate if changes were made. The Creative Commons Public Domain Dedication waiver (http://creativecommons.org/publicdomain/zero/1.0/) applies to the data made available in this article, unless otherwise stated. 
based on existing literature, could improve the management of these patients.

\section{References}

1. Torio CM, Andrews RM. National Inpatient Hospital Costs: The Most Expensive Conditions by Payer, 2011: Statistical Brief \#160. Healthcare Cost and Utilization Project (HCUP) Statistical Briefs. Rockville (MD) 2006.

2. Wang $Y$, Ouyang $Y$, Liu B, Ma X, Ding R. Platelet activation and antiplatelet therapy in sepsis: A narrative review. Thromb Res 2018;166:28-36. DOI: 10.1016/j.thromres.2018.04.007.

3. Tsao CM, Ho ST, Wu CC. Coagulation abnormalities in sepsis. Acta Anaesthesiol Taiwan 2015;53(1):16-22. DOI: 10.1016/j.aat.2014.11.002.

4. Salat A, Bodingbauer G, Boehm D, Murabito M, Tochkow E, Sautner $T$, et al. Changes of platelet surface antigens in patients suffering from abdominal septic shock. Thromb Res 1999;95(6):289-294. DOI: 10.1016/S0049-3848(99)00046-8.

5. Du F, Jiang P, He S, Song D, Xu F. Antiplatelet therapy for critically ill patients: A Pairwise and Bayesian network meta-analysis. Shock 2018;49(6):616-624. DOI: 10.1097/SHK.0000000000001057.

6. Ouyang Y, Wang Y, Liu B, Ma X, Ding R. Effects of antiplatelet therapy on the mortality rate of patients with sepsis: A meta-analysis. J Crit Care 2019;50:162-168. DOI: 10.1016/j.jcrc.2018.12.004.

7. Winning J, Reichel J, Eisenhut $Y$, Hamacher J, Kohl M, Deigner HP, et al. Anti-platelet drugs and outcome in severe infection: clinical impact and underlying mechanisms. Platelets 2009;20(1):50-57. DOI: 10.1080/09537100802503368.

8. Akinosoglou K, Alexopoulos D. Use of antiplatelet agents in sepsis: a glimpse into the future. Thromb Res 2014;133(2):131-138. DOI: 10.1016/j.thromres.2013.07.002.
9. Eisen DP, Moore EM, Leder K, Lockery J, McBryde ES, McNeil JJ, et al. Aspirin to inhibit sepsis (antisepsis) randomised controlled trial protocol. BMJ Open 2017;7(1):e013636. DOI: 10.1136/bmjopen-2016013636.

10. Kiers D, van der Heijden WA, van Ede L, Gerretsen J, de Mast Q, van der Ven $\mathrm{AJ}$, et al. A randomised trial on the effect of anti-platelet therapy on the systemic inflammatory response in human endotoxaemia. Thromb Haemost 2017;117(9):1798-1807. DOI: 10.1160/TH1610-0799.

11. Thomas MR, Outteridge SN, Ajjan RA, Phoenix F, Sangha GK, Faulkner $\mathrm{RE}$, et al. Platelet P2Y12 inhibitors reduce systemic inflammation and its prothrombotic effects in an experimental human model. Arterioscler Thromb Vasc Biol 2015;35(12):2562-2570. DOI: 10.1161/ ATVBAHA.115.306528.

12. Liverani E, Rico MC, Tsygankov AY, Kilpatrick LE, Kunapuli SP. P2Y12 receptor modulates sepsis-induced inflammation. Arterioscler Thromb Vasc Biol 2016;36(5):961-971. DOI: 10.1161/ ATVBAHA.116.307401.

13. Seidel M, Winning J, Claus RA, Bauer M, Losche W. Beneficial effect of clopidogrel in a mouse model of polymicrobial sepsis. J Thromb Haemost 2009;7(6):1030-1032. DOI: 10.1111/j.1538-7836.2009. 03352.x.

14. Sharron M, Hoptay CE, Wiles AA, Garvin LM, Geha M, Benton $A S$, et al. Platelets induce apoptosis during sepsis in a contactdependent manner that is inhibited by GPIlb/llla blockade. PLoS ONE 2012;7(7):e41549. DOI: 10.1371/journal.pone.0041549.

15. Valerio-Rojas JC, Jaffer IJ, Kor DJ, Gajic O, Cartin-Ceba R. Outcomes of severe sepsis and septic shock patients on chronic antiplatelet treatment: a historical cohort study. Crit Care Res Pract 2013;2013:782573. DOI: 10.1155/2013/782573. 